\title{
ESTUDO DE PRODUÇÃO DE UM SISTEMA DE CONTROLE DE MÁQUINAS DE TERRAPLENAGEM
}

\section{Study production of earthmoving machine control system John Fierro Sanhueza ${ }^{1}$, Patricia Herrera Diez ${ }^{2}$}

Recebido em 08 de outubro de 2014; recebido para revisão em 19 de novembro de 2014; aceito em 02 de dezembro de 2014; disponivel on-line em 22 de dezembro de 2014.

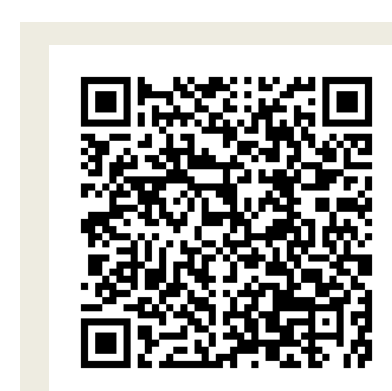

PALAVRAS CHAVE:

Terraplenagem;

Controle de máquinas,

Produtividade;

Construção civil.

* Contato com os autores:

${ }^{1}$ e-mail : john.fierro@gmail.com

2e-mail : patricia.herrera@gmail.com (P. H. Diez)

Engenheira Mecânica/Mecatrônica, da Pontifícia Universidade Católica de Minas Gerais.

\section{( J. F. Sanhueza )}

(J. F. Sanhueza)

on da Universidad de Santiago de Chile.
RESUMO: Os sistemas de controle de máquinas de terraplenagem têm se apresentado como uma solução tecnológica importante para a melhora da produtividade e qualidade dos trabalhos de movimentação de terras em obras da construção civil. Dentre essas soluções tecnológicas encontram-se os sistemas laser, sensores angulares, estações totais robóticas e receptores GPS/GNSS. Esta tecnologia permite a automação do movimento vertical da lâmina no trator de esteira e motoniveladora, e fornece informação visual do posicionamento da caçamba no referencial topográfico local da obra na escavadeira hidráulica. 0 aumento da produtividade mediante a utilização de um sistema de controle de máquina Duplo GNSS foi avaliada e comparada com a metodologia convencional de terraplanagem. $\mathrm{O}$ indicador analisado é o percentual de área no greide por hora e a qualidade da mesma em ambos os métodos. Experiências na implantação do sistema e conclusões a respeito ao incremento na produtividade e qualidade do trabalho em obras de construção civil são apresentadas.

v9i3.31986

(c) 2014 REEC - Todos os direitos reservados.

\section{INTRODUÇÃO}

As máquinas de terraplenagem são fundamentais nas obras de construção civil, pois possibilitam a conformação do relevo terrestre mediante o corte e aterro. Estas máquinas estão presentes em obras de distinta natureza, tais como a construção de rodovias e ferrovias, canais de irrigação e barragens e pátios industriais entre outras, as quais são utilizadas para preparar diferentes níveis de camadas de materiais segundo as especificações de um projeto.

A produtividade de operação nominal destas máquinas é determinada com base nas características de desenho e desempenho de cada modelo, entretanto umas séries de fatores inerentes ao ambiente operacional podem impactar negativamente. Dentre estes fatores uns dos mais influentes é o nível de experiência do operador (CATERPILLAR ${ }^{\circledR}, 2012$ ), sendo que este pode ser impactada positivamente através do uso da tecnologia do controle de máquinas (JONASSON et al. 2002).

Ao longo dos anos alguns sistemas tecnológicos foram desenvolvidos com o intuito de incrementar a produtividade e melhorar a qualidade nas operações de terraplenagem, permitindo assim controlar os movimentos do implemento da máquina de forma automática. É comum agrupar estes sistemas como do tipo 2D ou 3D, segundo o referencial de posicionamento que controlam. Os sistemas $2 \mathrm{D}$ são aqueles que trabalham considerando um plano como referência e que permitem visualizar e controlar 
apenas a elevação do implemento. Neste grupo encontram-se os sistemas de ultrassom, laser e sensores angulares. Os sistemas 3D são aqueles com a capacidade de interpretar um modelo digital do projeto e controlar as coordenadas $(x, y, z)$ do implemento. Neste grupo encontram-se os sistemas mais sofisticados, tais como a estação total robótica e os receptores GNSS (Global Navigation Satellite Systems).

As principais aplicações dos sistemas de controle de máquinas encontram-se nos segmentos da construção civil e mineração. As máquinas que normalmente recebem esta tecnologia são: o trator de esteira, a motoniveladora e escavadeira hidráulica (RETSCHER, 2002), embora seja possível encontrar estes sistemas de controle nas aplicações de pavimentação, compactação, assim como no segmento da agricultura de precisão. Alguns fabricantes de máquinas facilitam a implantação oferecendo ao mercado modelos preparados para o uso desta tecnologia.

Este trabalho apresenta aspectos sobre a implantação e operação do sistema de controle de máquinas 3D AccuGrade ${ }^{\circledR}$ dos fabricantes Trimble ${ }^{\circledR}$ e Caterpillar ${ }^{\circledR}$, na modalidade Duplo GNSS, quando aplicado numa obra de construção civil. As máquinas objetos deste estudo foram o trator de esteira $\mathrm{CAT}^{\circledast} \mathrm{D} 6 \mathrm{~T}$, operado no modo automático para o controle dos movimentos verticais da lâmina e a escavadeira hidráulica CAT $^{\circledR}$ 320D, operada no modo indicativo. Uma análise comparativa e relação entre o método convencional de trabalho e a utilização do sistema de controle de máquinas foram realizadas para determinar o acréscimo da produtividade.

\section{SISTEMA DE CONTROLE DE MÁQUINAS DE TERRAPLENAGEM}

Os sistemas de controle de máquinas proporcionam de modo geral um expressivo aumento de eficiência na etapa de terraplenagem, a qual pode ser quantificada através do aumento da produção diária e a diminuição do retrabalho na obra (BALLESTER et al. 2000). A operação em campo ganha autonomia e permite reduzir significativamente custos associados ao processo construtivo.

Durante a operação de terraplenagem convencional é necessária uma equipe de topografia, a qual materializa o projeto em campo através do processo de estaqueamento. As estacas locadas constituem para o operador uma referência visual parcial sobre as necessidades de corte e aterro da obra, sendo necessário o auxílio do "greidista" como apoio. É comum que o estaqueamento seja um processo demorado e deva ser realizado inúmeras vezes, pois normalmente estas estacas são removidas acidentalmente durante a operação.

Os sistemas de controle de máquinas caracterizam-se por reduzir esse processo de estaqueamento, sendo os diferentes sensores embarcados na máquina e um computador de bordo os que realizam a função de interface entre o projeto e o campo. O computador de bordo é responsável de fornecer em todo instante a posição do implemento através da sinalização gráfica e numérica, assim como converter essas informações em requisitos de corte ou aterro com base nas superfícies criadas a partir do modelo digital do projeto em formato CAD (Computer Aided Designs).

Desenhos geometricamente complexos contendo curvas horizontais e verticais, assim como diferentes seções transversais ao longo de uma rodovia podem ser contidas no projeto, sendo necessário neste caso um sistema de controle de máquinas tipo 3D.

Outra importante característica dos sistemas de controle é a capacidade de destacar a informação conhecida do entorno de trabalho, permitindo proteger entidades não visíveis para o operador, tais como, tubulações e fios subterrâneos, pois o operador na cabine pode visualizar a posição desses elementos existentes mapeados previamente e disponibilizados no computador de bordo (SCHREIBER, et al. 2008). Ainda é possível delimitar preliminarmente locais específicos onde não é permitido operar por questões de segurança ou de meio-ambiente. 
Segundo a tolerância requerida na execução da operação, o controle de máquinas pode empregar um emissor e receptor laser ou uma estação total robótica para atingir precisões entre \pm 5 e $\pm 10 \mathrm{~mm}$, porém quando a tolerância possui um nível de exigência menor o sistema GNSS em tempo real ou RTK (Real Time Kinematic) é empregado atingindo precisões de até $\pm 20 \mathrm{~mm}$.

Os sistemas de controle 3D podem ser operados em modo indicativo, no qual o operador recebe orientações através do computador de bordo embarcado na cabine ou no modo automático, no qual o operador apenas preocupase com a trajetória da máquina, sendo o computador de bordo responsável por controlar o movimento vertical da lâmina. Para automação do movimento vertical da lâmina é necessário o acionamento eletro-hidráulico, desta forma o computador embarcado na cabine tem a capacidade não apenas calcular os requisitos de corte ou aterro, assim como também de convertêlos em sinais elétricos para movimentação hidráulica por meio das eletroválvulas. As máquinas que não possuem o acionamento eletrohidráulico instalado de fábrica podem ser instrumentadas para obter a mesma capacidade.

A configuração do sistema 3D mais conhecido é o sistema Duplo GNSS, o qual possui um par de receptores GNSS RTK, que permitem o posicionamento e orientação da lâmina. Este tipo de sistema fornece um ótimo desempenho em locais onde existem inclinações transversais e longitudinais. Ainda quando instalado em motoniveladora ou trator de esteiras, este sistema torna o cálculo de posicionamento simples, uma vez que a posição da lâmina é conhecida em ambas às extremidades, evitando a necessidade de instalação de sensores adicionais para determinar a inclinação transversal e giro da mesma. Neste caso, o uso de sensores angulares é dispensado, sendo apenas empregados como redundância do sistema caso um dos receptores falhe. A Figura 1 apresenta os componentes do sistema de controle de máquinas 3D Duplo GNSS para trator de esteiras.

Em contrapartida, a instalação do sistema Duplo GNSS em escavadeiras hidráulicas requer um conjunto de sensores angulares para determinar o posicionamento da caçamba, além dos receptores GNSS RTK. Os sensores angulares coletam as inclinações da lança, braço e caçamba durante a operação, permitindo conhecer as coordenadas dos dentes em tempo real (TRIMBLE, 2013). A Figura 2 apresenta os componentes do sistema de controle de máquinas 3D Duplo GNSS para escavadeira hidráulica.

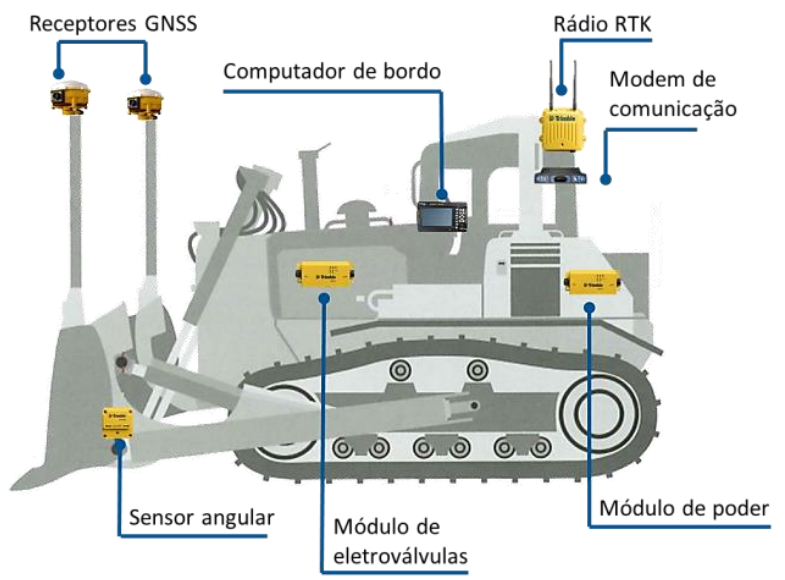

FIGURA 1: Componentes do sistema de controle de máquinas 3D Duplo GNSS para trator de esteiras. FONTE: TRIMBLE (2013).

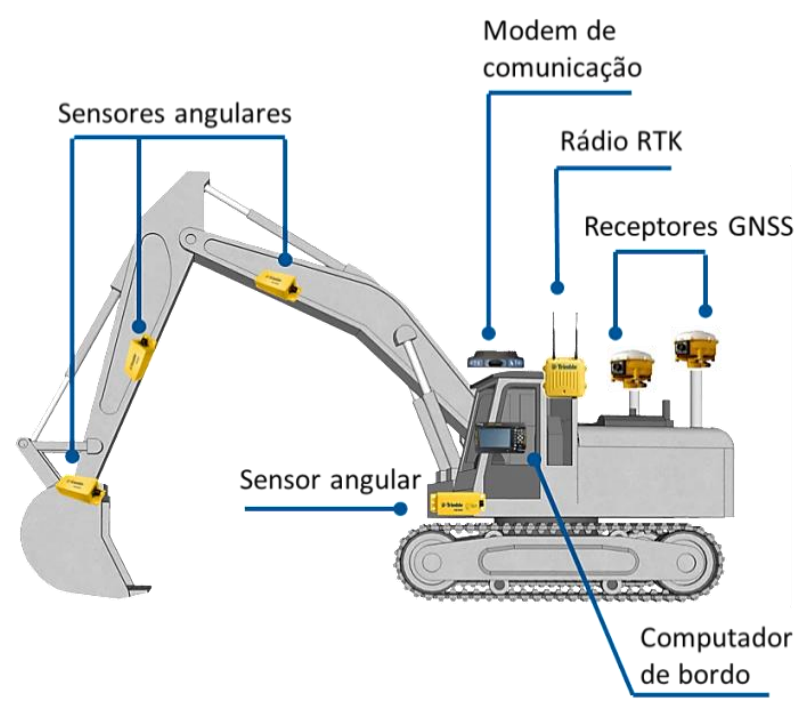

FIGURA 2: Componentes do sistema de controle de máquinas 3D Duplo GNSS para escavadeira hidráulica. FONTE: TRIMBLE (2013).

Dispositivos de comunicação tipo WiFi e $3 G$ proporcionam conectividade à Internet para o envio e armazenamento de dados de produção e registro da qualidade da operação. Estes dados são locados em servidores web possibilitando ainda o monitoramento e acompanhamento do local caso necessário assistência remota aos operadores. 


\section{METODOLOGIA}

Para o estudo e análise da produção foi empregado o sistema de controle de máquinas 3D Duplo GNSS AccuGrade ${ }^{\circledR}$. Os componentes do controle de máquina foram instalados em ambas as máquinas, o sistema de coordenadas topográficas da obra foi compatibilizado e um projeto foi preparado com base no arquivo CAD. Este representa matematicamente a superfície a ser construída e deve ser convertido para um modelo digital 3D no formato compatível com o computador de bordo das máquinas $e$ equipamentos de topografia.

No estudo considerou-se o modo de operação automático para um trator de esteira Caterpillar ${ }^{\circledR}$ D6T e modalidade indicativa para a escavadeira hidráulica Caterpillar ${ }^{\circledR}$ 320D. A operação de terraplenagem avaliada foi a construção de dois taludes (Talude1 e Talude2) e duas plataformas horizontais (Plano1 e Plano2). Um modelo digital contendo as seções transversais ao longo dos trechos avaliados foi criado. A Figura 3 apresenta um esboço do projeto criado e embarcado no computador de bordo para o controle de máquinas.

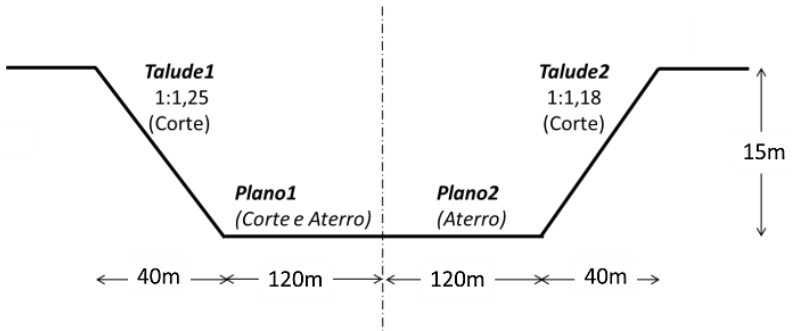

FIGURA 3: Esboço do projeto embarcado no do sistema de controle de máquinas 3D Duplo GNSS.

FONTE: Elaboração própria.

O trator de esteiras D6T foi avaliado nas operações de corte no Talude1 e no Talude2, a operação de corte e aterro no trecho Plano1 e considerou-se $\mathrm{o}$ espalhamento de material rochoso grosso e fino no caso do trecho Plano2.

A escavadeira hidráulica foi avaliada nas operações de corte no Talude1 e no Talude2. O requisito de precisão foi de $\pm 4 \mathrm{~cm}$ para que 0 trecho acabado fosse considerado dentro do greide, ou seja, dentro a tolerância do projeto. Dados de desempenho foram coletados para ambas as máquinas, levando em consideração a operação em ambientes operacionais idênticos e contendo os mesmos requisitos de corte e aterro.

Segundo JURADO e CLEVES (2005) a produção $(\mathrm{P})$ do trator de esteiras, pode-se obter pelo produto da carga útil da lâmina (Cu), o número de ciclos por hora (Ch), o fator de eficiência ( $\mathrm{Fe}$ ) obtido no manual de desempenho do fabricante da máquina e um fator de declividade no local de operação (Fp), conforme apresentado na Equação 1.

$$
P=C u \times C h \times F e \times F p
$$

Onde:

$\mathbf{P}=$ produtividade da operação $\left(\mathrm{m}^{3} / \mathrm{h}\right)$;

$\mathrm{Cu}$ = carga útil, capacidade da lâmina vezes fator volumétrico para cada tipo de material $\left(\mathrm{m}^{3} / \mathrm{h}\right)$;

$\mathbf{C h}=$ ciclos por hora;

$\mathbf{F e}=$ fator de eficiência segundo tipo de operação;

$\mathbf{F p}=$ fator de declividade no local de operação da máquina.

O modelo de produtividade apresentado na Equação 1 é quantitativo e não fornece uma métrica da qualidade da operação, pois considera somente o volume de material movimentado por unidade de tempo, levando em consideração a capacidade da lâmina da máquina e fatores tabulados dependendo do tipo de operação e declividade local.

Outro modelo quantitativo pode ser empregado relacionando o diferencial de volume inicial e final em uma unidade de tempo. O diferencial do volume pode ser obtido com o auxilio de uma equipe de topografia. A qualidade neste modelo de produtividade não é considerada.

Nesta abordagem e conforme o apresentado na Equação 2, foi avaliada a área finalizada como dentro do greide por unidade de tempo. Este modelo é quantitativo e qualitativo, pois representará também a qualidade da operação nos casos estudados.

$$
P m=\frac{A t \times(1-A f)}{T o+T e-T n}
$$

Onde:

Pm = produtividade da operação $\left(\mathrm{m}^{2} / \mathrm{h}\right)$;

At $=$ área total trabalhada $\left(\mathrm{m}^{2}\right)$;

Af = porcentagem de área fora do greide (\%); 
To = tempo total da operação (h);

Te = tempo de estaqueamento topográfico $(h)$;

$\mathrm{Tn}=$ tempo inoperante durante a operação $(\mathrm{h})$.

O modelo de produtividade apresentado na Equação 2, representa o nível de desempenho e considera a qualidade da operação realizada na etapa de acabamento da terraplenagem e não pretende representar o volume de material movimentado. Neste estudo o retrabalho necessário para correção do acabamento quando realizada sem sistema foi desconsiderado.

Com o objetivo de realizar uma análise comparativa da produtividade entre o método convencional e uso de um sistema de controle de máquinas, foram coletados durante duas semanas os dados da área percorrida por hora nos períodos diurno e noturno.

Dois cenários foram criados para o estudo comparativo, o primeiro empregando o método convencional sem o sistema $(A)$ e o segundo com o sistema de controle de máquina 3D Duplo GNSS AccuGrade $^{\circledR}$ (B). Estes cenários foram criados para cada tipo de aplicação nos taludes e nas plataformas horizontais, evitando assim que uma aplicação fosse beneficiada em detrimento de outra devido à facilidade de execução. A Figura 4 apresenta os cenários avaliados considerando os mesmos requisitos de corte e aterro em ambos os casos.

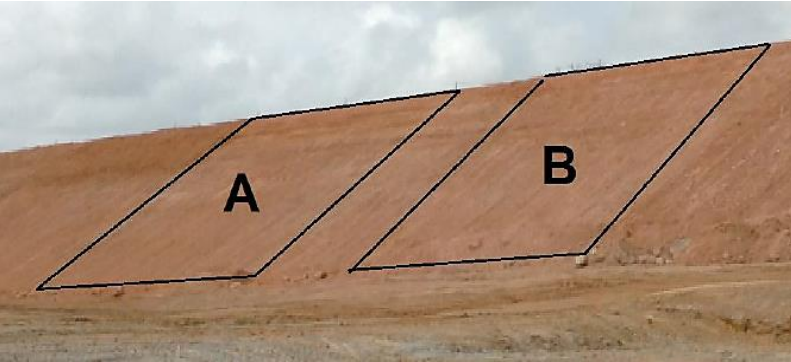

FIGURA 4: Cenários avaliados: (A) método convencional e (B) sistema de controle de máquinas 3D Duplo GNSS. FONTE: Elaboração própria.

Foram observados os tempos de operação, desconsiderou-se o tempo de parada da máquina e acrescentou-se os minutos empregados pela equipe de topografia para o estaqueamento quando requerido no método convencional. A equipe de operadores das máquinas realizou a operação nas mesmas condições quanto à quantidade de corte e aterro requisitada em cada cenário.
Durante a operação e quando a lâmina encontra-se próximo ao projeto o operador ativa o funcionamento do modo automático, embora seja possível empregar antes dessa fase com o auxilio de offsets verticais. Para o caso da operação na escavadeira hidráulica o controle de máquinas foi avaliado no modo indicativo.

Uma vez que a área foi concluída pelo operador, um levantamento topográfico foi realizado. A análise considera um processamento de dados e geração de superfícies tridimensionais com base nos levantamentos topográficos para comparação com a superfície do projeto.

\section{RESULTADOS}

Para exemplificar os resultados comparativos, a figuras a seguir apresentam o resumo das operações avaliadas para o trator de esteiras.

A Figura 5 apresenta o percentual de área no greide. Pode-se verificar que sendo uma operação de corte no Talude1, o operador com o sistema de controle de máquinas no modo automático obteve $95 \%$ da área trabalhada no greide com uma precisão de $\pm 4 \mathrm{~cm}$, sendo que com o método convencional obteve-se $14 \%$. Resultados similares foram obtidos na operação de corte no Talude2, no qual o sistema de controle obteve $88 \%$ da área no greide e o método convencional obteve 15\%. Analisando estes resultados pode-se notar que nem a declividade do talude nem o tipo de compactação de material, embora similares, foram fatores diferenciais para o resultado final.

Observa-se ainda na Figura 5 que na operação de corte e aterro no trecho Plano1 o sistema de controle obteve $84 \%$ da área no greide com uma precisão de $\pm 4 \mathrm{~cm}$. Uma estimativa do método convencional indica que neste trecho o $18 \%$ da área está dentro a mesma precisão, mantendo-se a tendência anterior. Os resultados mostram que praticamente o sistema não teve distinção ao tipo operação e nem o diferencial de declividade foi um fator influente no resultado final.

Para o trecho Plano2 onde a principal 
operação é o aterro de espalhamento de material, o efeito de afundamento do terreno foi um fator que teve influência no resultado. A área no greide com precisão de $\pm 4 \mathrm{~cm}$ com o uso do sistema de controle de máquinas foi de $71 \%$, sendo que o com método convencional obteve-se $18 \%$ na mesma estimativa anterior. De modo geral podese observar que o sistema de controle de máquinas 3D Duplo GNSS no modo automático obteve entre quatro e cinco vezes mais qualidade quando comparado com o método convencional.

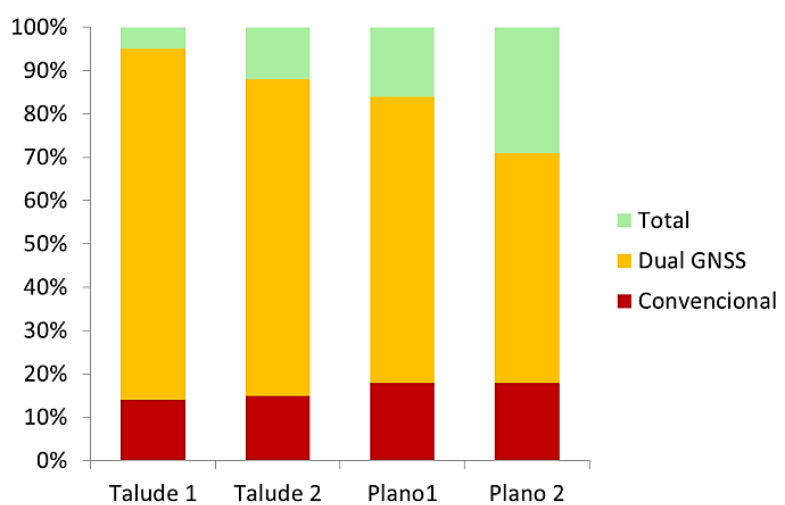

FIGURA 5: Percentual de área no greide com precisão de $\pm 4 \mathrm{~cm}$ para trator de esteiras.

FONTE: Elaboração própria dos autores (2014).

A Figura 6 apresenta a relação de avanço de área no greide percorrida por hora $\left(\mathrm{m}^{2} / \mathrm{h}\right)$. No Talude1 o sistema de controle obteve $347 \mathrm{~m}^{2} / \mathrm{h}$, sendo que com o método convencional foi 68 $\mathrm{m}^{2} / \mathrm{h}$. Uma relação similar entre ambos os métodos mantem-se no Talude2, sendo $273 \mathrm{~m}^{2} / \mathrm{h}$ finalizados dentro do greide com o sistema e 39 $\mathrm{m}^{2} / \mathrm{h}$ com o método convencional.

O acabamento com o sistema no modo automático no trecho Plano1 foi de $233 \mathrm{~m}^{2} / \mathrm{h}$ e com o método convencional foi $68 \mathrm{~m}^{2} / \mathrm{h}$, ambos os casos com requisitos de corte e aterro semelhante. No trecho Plano2, na operação de aterro com o sistema de controle automático obteve-se 572 $\mathrm{m}^{2} / \mathrm{h}$ no greide, sendo que com o método convencional obteve-se $113 \mathrm{~m}^{2} / \mathrm{h}$.

Pode-se notar na Figura 6, que a relação de avanço entre o sistema de controle de máquinas Duplo GNSS e o método convencional de terraplenagem é aproximadamente cinco para um, sendo por tanto cinco vezes mais eficiente o sistema de controle de máquinas.

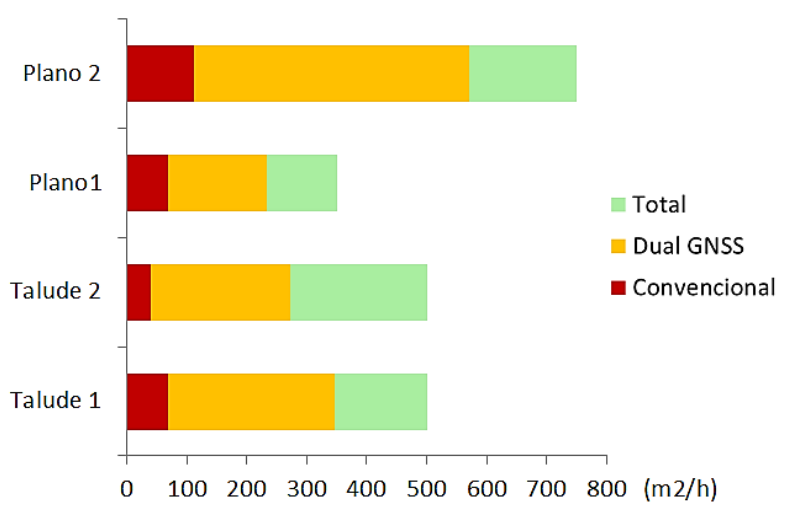

FIGURA 6: Relação de avanço de área no greide percorrida por hora $\left(\mathrm{m}^{2} / \mathrm{h}\right)$ para trator de esteiras. FONTE: Elaboração própria dos autores (2014).

A Figura 7 apresenta o percentual de área no greide. Verifica-se que no Talude1 o operador com o sistema de controle de máquinas no modo indicativo obteve $76 \%$ da área trabalhada dentro do greide com uma precisão de $\pm 4 \mathrm{~cm}$, sendo que com o método convencional obteve-se $41 \%$. Resultados similares quanto à precisão foram obtidos no Talude2, no qual o sistema de controle obteve $78 \%$ da área no greide e o método convencional obteve $40 \%$.

Analisando estes resultados pode-se notar que nem a declividade do talude nem o tipo de compactação de material, embora similares, foram fatores diferenciais para o resultado final. De modo geral pode-se observar que o sistema de controle de máquina Duplo GNSS no modo indicativo para a escavadeira hidráulica obteve duas vezes mais qualidade quando comparado com o método convencional.

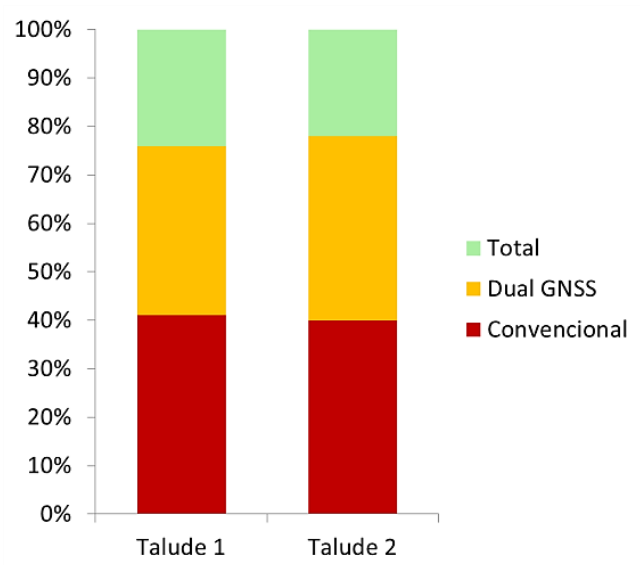

FIGURA 7: Percentual de área no greide com precisão de $\pm 4 \mathrm{~cm}$ para escavadeira hidráulica.

FONTE: Elaboração própria dos autores (2014). 
A Figura 8 apresenta a relação de avanço de área no greide percorrida por hora $\left(\mathrm{m}^{2} / \mathrm{h}\right)$. No Talude1 o sistema de controle obteve $104 \mathrm{~m}^{2} / \mathrm{h}$, sendo que com o método convencional foi 62 $\mathrm{m}^{2} / \mathrm{h}$. No caso do Talude2 a relação entre ambos é ainda maior e favorável ao sistema de controle indicativo, pois obteve-se $58 \mathrm{~m}^{2} / \mathrm{h}$, quando o método convencional obteve $23 \mathrm{~m}^{2} / \mathrm{h}$. Neste caso a produtividade é menor quando comparada com - Talude1 devido às manobras de remoção do material excedente necessárias durante a operação neste talude. De modo geral a relação de avanço entre o sistema de controle de máquinas Duplo GNSS no modo indicativo e o método convencional de terraplenagem é aproximadamente dois para um, sendo por tanto duas vezes mais eficiente o sistema de controle de máquinas nesta operação.

Talude 2

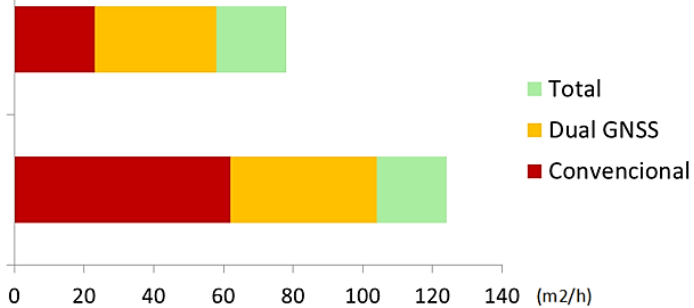

FIGURA 8: Relação de avanço de área no greide percorrida por hora $\left(\mathrm{m}^{2} / \mathrm{h}\right)$ para escavadeira hidráulica. FONTE: Elaboração própria dos autores (2014).

Ganhos qualitativos também foram observados ao longo deste estudo. O primeiro é o fator de eficiência do operador, pois ele segue referencias visuais no computador de bordo e não simplesmente a sua intuição para manter a lâmina da máquina no greide. A perda de qualidade entre as estacas foi eliminada por isso a área no greide é expressivamente maior com o sistema de controle. A informação em tempo real e visibilidade dos requisitos de corte e aterro foi um ganho que permitiu reduzir tempo de operação, pois o operador conseguiu realizar menos manobras de deslocamento da máquina para iniciar a operação, permitindo inclusive a escavação em pontos não visíveis no caso da escavadeira hidráulica. O tempo de operação foi reduzido consideravelmente permitindo autonomia aos operadores e a eliminação da dependência ao pessoal de apoio externo à máquina, consequentemente aumentando segurança das equipes em campo.

\section{CONSIDERAÇÕES E CONCLUSÕES}

A automação do sistema de controle de máquinas permitiu uma maximização da produtividade na operação de terraplenagem, sendo expressivo o ganho qualitativo do trabalho de acabamento. O modelo de quantificação da produtividade apresentado permitiu obter métricas para mensurar a qualidade da operação realizada.

Para este estudo de caso e quando empregado o sistema de controle de máquinas Duplo GNSS, a dinâmica operacional desta obra permitiu um acréscimo de produtividade em torno quatro ou cinco vezes no trator de esteiras D6T e duas vezes na escavadeira hidráulica 320D. Resultados semelhantes podem ser alcançados em outras aplicações se houver uma sincronia entre as equipes de campo e do projeto. Estas equipes devem se coordenar de forma passar a atender a nova dinâmica da obra que será requisitada na utilização do sistema de controle de máquinas. Quanto à precisão e qualidade da terraplenagem na etapa de acabamento obteve-se um aumento de seis vezes no trator de esteiras D6T e duas vezes para a escavadeira hidráulica 320D.

Este aumento de desempenho e qualidade teve sua principal justificativa na automação e informação em tempo real dos requisitos de corte ou aterro, sendo o movimento vertical da lâmina no trator de esteiras completamente automatizado. Operações nas quais o operador utiliza apenas a metade da lâmina da máquina e assim copiar uma referência existente foram eliminadas, pois o operador passou a ter a autonomia suficiente com a informação providenciada pelo computador de bordo. A informação em tempo real do posicionamento da caçamba na escavadeira hidráulica em relação ao projeto também forneceu uma vantagem operacional, pois o operador diminuiu a quantidade de manobras necessárias para posicionar a máquina. Operadores com 
diferentes níveis de experiência foram equalizados, sendo capazes de entregar um acabamento de qualidade com o mínimo de tempo e esforço, independente se o período de operação foi diurno ou noturno.

Benefícios diretos não mensurados foram identificados, os quais apresentam-se pelo aumento da segurança e desempenho de operadores pouco experientes, a redução significativa retrabalho da operação de terraplenagem e diminuição do trabalho de acompanhamento da equipe de topografia na demarcação, estaqueamento e colocação de cruzetas. Custos operacionais foram reduzidos após a implantação do sistema, sendo a eliminação da utilização de materiais nobres para cobrir erros de execução na terraplenagem e economia de combustíveis notórias ao longo de todo o processo de avaliação.

\section{REFERÊNCIAS BIBLIOGRÁFICAS}

BALLESTER F., CASTRO D., LÓPEZ-CUERVO S. Los sistemas de control para maquinaria de movimiento de tierras. Revista de Obras Públicas. Cantabria - Espanha, 2000.

CATERPILLAR $^{\circledast}$ INC, Manual de desempenho da Caterpillar para tratores de esteiras. Peoria, Illinois - EUA, 2012.

CATERPILLAR $^{\circledR}$ INC, Road Construction Production Study. Malaga Demonstration \& Learning Center. Malaga - Espanha, 2006.

JONASSON S., DUNSTON P., AHMED K., HAMILTON J. Factors in Productivity and Unit Cost for Advanced Machine Guidance. Journal of Construction Engineering and Management, 2002.

JURADO J., CLEVES G. Estudios de Movimientos de Tierra. Facultade de Ingeniería, Armenia, Universidad del Quindío, 2005.

RETSCHER G., Multi-Sensor Systems for Machine Guidance and Control. FIG XXII International Congress. Washington D.C - EUA, 2002

SCHREIBER F., DIEGELMANN M., RAUSCH P., Use of a Machine Control \& Guidance System, Determination of Excavator Performance, Cost Calculation and Protection Against Damaging of Pipes and Cables. 1st International Conference on Machine Control \& Guidance, 2008.

TRIMBLE NAVIGATION LTD., GCS900 Grade Control System Site Supervisor's Manual, Engineering and Construction Division. Dayton, Ohio - EUA, 2013. 